\title{
Estudio Comparativo de Dos Métodos en el Diagnóstico de Rotavirus en Lactantes con Diarrea Aguda y Asintomáticos
}

\author{
Dra. Magdalena Araya Q.; Sr. Eugenio Spencer O.; Dr. Oscar Brunser T.; \\ Dr. Jutio Espinoza M.: Sra. Ana María Sandino G.1
}

\author{
Elisa and Gel Electrophoresis of Viral RNA in The Diagnosis of Rotavirus Infection
}

\begin{abstract}
Comparison of positive rates of rotavirus identification obtained with an ELISA technique and gel electrophoresis of viral RYA was carried out in 88 infants with diarrhoea and 63 age matched asymptomatic controls, surveyed during a tield study. In patients with diarrhoea, $37.5 \%$ had at least one of the tests positive, but only $22.7 \%$ had positjve gel electrophoresis logether with ELISA 3 to $4+$. Chi square andlysis showed that the association between positive electrophoresis of viral RNA and ELISA 3 to 4 + was significant $(\mathrm{p}<0.05)$, but this was not so when ELISA was 1 or $2+$. Among asymptomatic subjects, 4 (6.3\%) showed strands of rotavirus RXA at the electrophoresis, while their ELISA test was 1 or $2+$. In other wo chjlden gel electrophoresis was negative and ELISA was 3 and $4+$, respectively, suggesting that these infants were excreting incomplete viral particles, not identifiable as rotavirus by the electrophoresis method.

(Key words: Açute Diarhoca. Rotavirus Infection. Elisa. Gel Llectrophoresis. Viral RNA. Lthiology).
\end{abstract}

Los rotavirus causan diarrea aguda en gran variedad de especies arimales, incluyendo el hombre ${ }^{1-2}$. En paises desarrollados ${ }^{3}$ y en algunas áreas en desarrollo ${ }^{4}$ es el agente más frecuentemente identificado en las heces de nin̄os con diarrea aguda.

En Chile, se ha identificado at agente en 10 a $25 \%$ de pacientes hospitalizados y en alrededor de $15 \%$ de casos ambulatorios de diarrea $5-8$. Estos porcentajes representati promedios, pues la frecuencia de identificación del virus varía considerablemente sègún la estación, el año en que se efectúe el estudio y la edad del grupo evaluado.

Sc ha argumentado que parte de las diferencias de frecuencia publicadas podrían deberse a distinto rendiniento de los métodos empleados para detectar rotavirus9-10. Esta investigación se realizó para comparar los resultados obtenidos con el método de electroforesis en gel (que identifica el RNA viral) y los de la técnica de ELISA (que reconoce la presencia de antigenos virales por métodos inmunológicos); establecer relaciones entre ambos procedimientos, cotcjar resultados con las caracteristicas clínicas de] episodio de diarrea $y$, finalmente, comparar la

1. Instituto de Nutrición y Tecnología đe los Alimentos. información que aportaban los dos métodos en pacientes con diarrea y controles asintomáticos.

\section{MATERIAL Y METODO}

Se siguió prospectivamente una cohorte de 104 lactantes menores de un año, destetados espontáneamente por lo menos 15 dís antes del ingreso al protocolo, eutróficos o con grados leves de desnutrición, durante 12 meses. Sus madres fueron contactadas. recibieron explicaciones sobre el cstudio y autorizaron ia participación de cada nit̃o, firmando un consentimjento escrito.

Cada familia fue visitada dos veces por semana en su casa; en cada ocasión se registró sj el niño sufria de diarręa aguda. definiéndola como eljminación de deposiciones liquidas o aumento del numero de evacuaciones intestinales en por lo menos dos, sobre el hábito normal de cada sujeto en un período de 24 horas. Se recolectó información acerca de las características clinicas de la diarrea y se tomó una muestra fecal de alrededor de 3 gramos que se depositó en un frasco sin fijador, manteniéndolo en hielo hasta entregarlo en el Laboratorio de Virologia. Alli se congeló a menos $20^{\circ} \mathrm{C}$ hasta su procesamiento, que se efectuó en los próximos 7 dias. Se obtuvieron 
también muestras para estudios bacteriológicos y parasitarios cuyos resultados detallados serán publicados posteriormente.

Además de los controles domiciliarios, los niños fueron pesados $y$ medidos una vez por mes en una consulta montada especialmente para los fines del proyecto, a la que tuvieròn libre acceso para atención médica y de enfermería por otras afecciones. En estas ocasiones los datos perti. nentes fueron registrados en cada caso.

Cada dos episodios de diarrea se tomó una muestra fecal, de iguales características a las descritas anteriormente, en un "control" asintomático, pareado por edad; sin antecedentes de diarrea en las últimas tres semanas y que se mantuvieran sin ella durante los 7 dias siguientes a la obtención de la muestra.

La presencia de rotavirus en las heces se investigó mediante electroforesis en gel y una técnica de ELISA que emplea un aquipo comercial.

La muestra fecal se diluyó en tampón $50 \mathrm{mMtris}-\mathrm{HCl} \mathrm{pH} 8.4$ en proporción de 2: ]. D esta manera se usaron $200 \mu \mathrm{l}$ para el ensayo de ELISA y $1 \mu 1$ para la electroforesis en gel.

Para el ensayo en geles de poliacrilamida se usó un procedimicnto previamente descrito ${ }^{11}$, diluyendo las muestras de deposiciones en un volumen de Freón $T F$, que se homogenizó $y$ centrifugó a $3.000 \mathrm{rpm}$ por 30 minutos. El sobrenandante fue precipitado con polietilenglicol por incubación a $0^{\circ} \mathrm{C}$ por 12 horas y luego recolectado por centrifugación a $5.000 \mathrm{rpm}$ durante 30 minutos, descartándose el sobrenadante. El precipitado se resuspendió en $100 \mu l$ de tampoon $200 \mathrm{mMtris} \mathrm{HCl} \mathrm{pH} 8,4,50 \mathrm{mM} \mathrm{NaCl} y$ $0,1 \%$ de sodio dodecilsulfato. La muestra fue extraída con un volumen de fenol saturado en el mismo tampón, con el fìn đe desprotcinizar la muestra

El resultado de la técnica de ELISA se consideró positjvo cuando se desarrolló color. De acuerdo con las instrucciones de los fabricantes y según la intensidad del color producido los resultados positiyas se expresaron en escala de 1 a $4+$.

En presencia del genomio viral, la elcctroforesis pcrmite visualizar en el gel l l bandas típicas del RNA de rotavirus, lo que se definió como resultado positivo.

\section{RESULTADOS}

Se estudiaron 88 lactantes con diarrea, cuyas edades fluctuaban entre 3 y 10 meses (43 varones), y 63 niños asintomáticos entre 2 y 11 meses
Tabla 1.

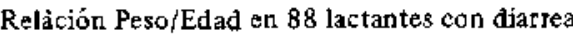
y 63 asintomáticos

\begin{tabular}{|c|c|c|c|c|}
\hline \multirow{2}{*}{$\begin{array}{c}\text { \% Estándar } \\
\text { NCHS }\end{array}$} & \multicolumn{2}{|c|}{$\begin{array}{l}\text { Lactantes con } \\
\text { Diartea }\end{array}$} & \multicolumn{2}{|c|}{$\begin{array}{c}\text { Lactantes } \\
\text { Asintomáticos }\end{array}$} \\
\hline & $\mathrm{P} / \mathrm{E}$ & $\mathrm{T} / \mathrm{E}$ & $\mathrm{P} / \mathrm{E}$ & $\mathrm{T} / \mathrm{E}$ \\
\hline $75-80$ & 5 & 1 & 2 & 0 \\
\hline $81-90$ & 5 & 17 & 6 & 0 \\
\hline $91-105$ & 50 & 45 & 31 & 39 \\
\hline $106-120$ & 20 & 21 & 21 & 24 \\
\hline 120 & 4 & 3 & 2 & 0 \\
\hline TOTAL & $87^{*}$ & $87^{* *}$ & $62^{*}$ & 63 \\
\hline
\end{tabular}

* En un niño no se obtuvo las medidas antropomé tricas necesarias para el cálculo de $\mathbf{P} / \mathrm{E}$

* En un niño la talla no estaba disponible para el ¿álculo de T/E.

Tabla 2.

Resultados positivos obtenidos por electroforesis en gel y método de ELISA en 88 lactantes con diartes

\begin{tabular}{|c|c|c|c|}
\hline \multirow[b]{2}{*}{ ELISA } & \multicolumn{2}{|c|}{ Electroforesis en gel } & \multirow[b]{2}{*}{ TOTAL } \\
\hline & $(-)$ & $(+)$ & \\
\hline 0 & 0 & 2 & 2 \\
\hline+ & 7 & 2 & 9 \\
\hline++ & 6 & 6 & 12 \\
\hline$+1+$ & 0 & 8 & 8 \\
\hline++++ & 0 & 2 & 2 \\
\hline TOTAL & 13 & 20 & $33(37,5 \%)$ \\
\hline
\end{tabular}

( ) No se identificaron bandas de RNA viral en la electroforesis.

(十) Bandas de RNA viral identiticables en la electroforesis

de edad ( 34 varones). El estado nutricional evaluado por la relación peso para la cdad y talla para la edad se muestra en la Tabla 1. En el momento del cstudio ningún nin̄o recibía leche materna Los episodios de diarrea se detectaron en las primeras 72 horas de evolución y tuvieron una duración promedio de 4,4 dias (rango 1 a 10 días). Los sintomas fueron inespecificos y la evolución sin complicaciones: los pacientes no requirieron hospitalización. La deshidratación se estimó de menos de $5 \%$ en todos los çasos. En 13 lactantes se identificaron bacterias entcropatógenas, siete E. coli enteropatógenos serotipos clásicos, cuatro Shigellas, una E. coli enterotoxigénica y un Campylobacter jejuni; en 8 de los 13 se detectó además rotavirus. No hubo relación entre las caracteristicas clinicas y los agentes patógenos observados.

Los resultados de ELISA y electroforesis en gel en pacientes con diarrea se muestran en la Tabla 2 y para los controles en la Tabla 3. E1 análisis por chi cuadrado con 4 grados de libertad 
Tabla 3.

Resultados positivos obtenidos por electroforesis en gel y método de ELISA en muestras fecales de 63 lactantes asintomáticos

\begin{tabular}{|c|c|c|c|}
\hline EL]SA & $\begin{array}{c}\text { Electrof } \\
(-)\end{array}$ & sis en gel & TOTAL \\
\hline $\begin{array}{l}0 \\
+ \\
++ \\
++1 \\
++++\end{array}$ & $\begin{array}{l}0 \\
2 \\
2 \\
1 \\
1\end{array}$ & $\begin{array}{l}1 \\
2 \\
1 \\
0 \\
0\end{array}$ & $\begin{array}{l}1 \\
4 \\
3 \\
1 \\
1\end{array}$ \\
\hline TOTAL & $6(9,5 \%)$ & $4^{*}(6,3 \%)$ & 10 \\
\hline
\end{tabular}

$(-)$ y $(+)$ tienen el mismo significado que en la Tabla 2.

* Todos estos episodios fueron ELISA (-) si el criterio mínimo es 3 ó 4 .

mostró que la asociación entre electroforesis positiva y ELISA 3 o $4+$ era estadísticamente significativa $(\mathrm{p}<0,05)$, no asi entre electroforesis positiva y ELISA $1 \propto 2+$

No se encontró correlación entre el resultado de los exámenes (por lo menos uno positiva o ambos positivos) y la edad, el estado nutricional del sujeto, la duración del episodio, y la asocia. ción con otros enteropatógenos (bacterianos $y$ parasitarios) detectados. En relación a las variables mencionadas, tampoco se encontraron diferencias significativas entre los pacientes en que se detectó rotavirus y aquellos en que esto no ocurrió.

\section{DISCUSION}

En episodios de diarrea como los de esta investigación los resultados obtenidos con los métodos de ELISA y electroforesis en gel fueron variables. Si se toma como criterio para definir positividad del episodio que por lo menos uno de los dos métodos dé resultado positivo, $37.5 \%$ de ellos se podrian considerar relacionados con rotavirus. En cambio. si se exige que la electroforesis en gel sea positiva, sólo $22,7 \%$ de los casos parecerían asociados al virus. Esta proporción de identificación permanece igual si la exigencia es que la electroforesis sea positiva y ELISA sea positivo con $30^{\circ} 4$.

Se podría objetar el criterio de considerar la electroforesis en gel como punto de referencia para la identificación etiológica de un episodio, pues si bien el metodo es muy preciso (identifica las bandas típicas de RNA del rotavirus y no permite confusión con otros virus), se le ha criticado porque requiere la presencia de un número minimo de partículas virales en las heces (alrededor de $1 \times 10^{6} / \mathrm{cc}$ ) para que sea posible ver las 11 bandas de RNA. Conscientes de este problema obtuyimos muestras fecales de por lo menos 3. gramos, concentrándolas antes del análisis. Creemos que de esta manera se elimina el riesgo aludido. Por otro lado, la falta de precisión de los métodos de ELISA disponibles en el mercado ha sido reconocida en la literatura ${ }^{12}$. Por estos motivos, creemos que la electroforesis en gel o la rotaforesjs (método modificado de la electroforesis tradicional) son más apropiados como patrones de referencia. Si no se cuenta con estas técnicas y los estudios se realizan mediante ELISA, es necesario tener presente que ésta produce una proporción relativamente alta de falsos positivos, debiendo exigirse resultados 3 ó $4+$ para considerar que el episodio se relaciona con rotavirus.

Las característica clínicas de todos los sujetos con diarrea fueron parecidas. Esto no permitió comparar subgrupos para evaluar algunas varia. bles que pudieran influir en la severidad del episodio y el rendimiento de los métodos.

Los resultados obtenidos en niños asintomá. ticos son dificiles de interpretar si aplicamos el criterio enunciado para analizar los episodios de diarrea, pues los 4 casos positivos en la electroforesis fueron negativos en la prueba de ELISA y por otro lado, en los dos con ELISA positivo 3 y $4+$, respectivamente, la electroforesis fue negativa.

Los estudios de rotavirus en individuos asinto. máticos son escasos ${ }^{13-14}$, la mayoría en recién nacidos. Este periodo de la vida tiene características tan especiales que sería un error comparar los resultados obtenidos en él, con los de individuos de otras edades. Nuestros resultados se pueden explicar teniendo en cuenta que ELISA reacciona con antígenos de la cápside del virus, mientras que el gel detecta RNA viral. En este tipo de estudios no se sabe cuando el individuo entró en contacto con el virus y es posible que en el momento de efectuar la investigación, el organismo haya alcanzado cierto nivel de inmu nidad, de manera que predomine la eliminación de partículas incompletas. De esta manera, algunas particulas que representan antigenos reconoci. bles por los anticuerpos contenidos en el ELISA producen resultados positivos con este examen al thismo tiempo que no se logra reconocer las bandas de RNA de rotavirus en la electroforesis.

$\mathrm{Si}$ se acepta esta línea de pensamiento, 10 (15,9\%) niños asin tomáticos estaban excretando componentes de rotavirus, en 4 de ellos $(6,3 \%)$ se podía identificar el genomio viral de rotavirus y en $6(9,5 \%)$ componentes de las cubiertas exter- 
nas del virus.

El significado del hallazgo de rotavirus en las heces de niños asintomáticos sin antecedentes próximos de diarrea no está aclarado. Es un hecho demostrado que existen portadores de rotavirus $^{7}$. No se sabe si esto significa mayor riesgo de enfermat por ese agente para estos sujetos. Información obtenida en portadores de agentes bacterianos sugiere que ser portador de una bacteria enteropatógena no constituye un riesgo mayor de desarrollar enfermedad diarreica producida por la misma bacteria (datos no publicados). Desde el punto de vista de Salud Pública no cabe duda que el fenómeno de portación es importante, pues los portadores asintomáticos constituyen un reservorio para el agentc y una fuente potencial de infección para la comunidad.

\section{RESUMEN}

En 88 lactantes con diarrea y 63 coetáneos asintomáticos estudiados en tcrresı, se comparó el número de identificaciones de rotavirus obtenidos con una técnica de ELISA y electroforesis en gel. De los niños con diartea, en $37,5 \%$ se obtuvo por lo menos un resultado positivo con alguno de los dos métodos. El resultado de ELISA se calificó en 1 a $4+$. Sólo en $22,7 \%$ de las muestras coincidieron la electroforesis positiva con ELISA 3 ó $4+$. El análisis por $x^{2}$ con 4 grados de libertad mostró que esta asociación era estadisticamente significativa $(p<0,05)$, no asi la asocjación entre electroforesis positiva $y$ ELISA $1 \circ 2+$. En cuatro niños asintomáticos $(6,3 \%)$, se identificó RNA viral con la electroforesis en gel y ELISA fue $1 \dot{\alpha} 2+$. En otros dos niños, el ELISA fue positivo 3 y $4 F$, respectivamente, con electroforesis negativa, to que sugiere que estos últimos excretaban particulas virales incompletas no reconocibles como RNA de rotavirus mediante la electroforesis en gel.

\section{AGRADECIMIENTOS}

Este trabajo fue parcialmente financiado por Nestlé Research.

Deseamos expresar nuestros agradecimientos al Director del Consultorio La Faena, Dra. Lucía Toto, a la Enferinera lefe, Srta. Ima Riumalló y a todo el personal de dicho consultotio, sin cuyo apoyo este estudio no se habría podido realizar. Asimismo, agradecemos a nuestro personal de terreno y de laboratorio, especialmente a las Sras. Sara Labrín e Isolda Pacheco, por su excelente labor profesional.

\section{REFERENCIAS}

1. Mc Nulty M.S.: Rotaviruses. J. Gen. Virol. 40: 1 , 1978.

2. Flewett T.H.: Clinical features of rotavinus infectons. En: Tyrtell DAJ, Kapikian AZ, eds. Virus infection of the gastrointestinal tract. New York Decker. 125-145, 1982.

3. Kapikian A., Kim H., Wyatt R., Cline W., Arrobio S., Brandt C., Rodriguez W. Sack D., Chanock $R$. Parrot $R$.: Human reovirus-like agent as the mayor pathogen associates with "winter" gastroenteritis in hospitalized infants and young children. N. Engl. J. Med. 294: 965, 1976.

4. Black R.E., Brown K.H., Beckers, Abdul Alim ARH., Huq $J .:$ Longitudinal studies of infections diseases and physical growth of ehildren in rural Bangladesh. Am. J. Epidemiol. 115: 315, 1982.

5. Spencer E. A vendaño F. and Araya M.: Characteristics and analisis of electrophoretypes of human rotavirus isolated in Chile. J. of Infect. Dis. 148: 41 , 1983.

6. Avendafo L.F. Spencer E., Calderón A, y Martinez A.: Infección por rotavirus en lactantes con diarrea aguda. Rev. Med. Chile 111: 240, 1983.

7. Araya M., Figueroa G., Espinoza J., Montesinos $N$, Spencer $E$. Brunser $O$.: Acute diarrhoea disease in children under 7 years of age in a periurban slum of Santiago, Chile. J. Hyg. 1985, en prensa.

8. Figueroa G., Araya M., Ibánez S., Clerc N., Brunser $O$.: Enteropathogens associated to acute diarrhoea in hospitalized infants. J. Ped. Gastroenterol. Nutr. 1985, en prensa.

9. Birch C.J., Lehnann N.I., Hawker A.J., Marsholl J.A., Gust. I.D.: Comparison of electron microscopy, enzyme-linked immunosorbent assidy, solid-phase radioimnuno assay, and indirect immunofluorecence for detection of human fotavirus antigen in faeces. J. Clin. Pathol. 32: 700 , 1979 .

10. Hammond G.W., Ahluwalia G.S., Barker F.G. Horsmor G. Hazelton P.R.: Comparison of direct and indirect enzyme immunoassays with direct ultacentrigugation before electron microscopy for detection of rotavirus. J. Clin. Microbiol. 16:53, 1982.

11. Spencer E., Arias M.L.: In vitro transcriptor catalized by heat-treated human rotavirus. J. of Virology $40: 1,1981$.

12. Ghose L.H., Schnagl R., Holmes I.H.- Comparison of an enzyme-linked immunosorbent assay for quantification of rotarirus antibodies with complement fixation in an epidemiological survery. J. Clin. Microbiol. 8: 268, 1978.

13. Champsaur H., Henry-Amar M., Goldszmidt $D$. Prevot $J$, Bourouane $E$, Questioux E. and Bach $A$.. Rotavirus carriage, asymptomatic infection and disease in the first two years of life I virus shelding. II Serological Response. J. Infect. Dis. 149: 667 , $675,1984$.

14. Holmer I.H.: Viral gastroenteritis. Prog, Med. Virol. 25: 1,1979 . 